\title{
Role of Some Organic Compounds as Corrosion Inhibitors for 316L Stainless Steel in $1 \mathrm{M} \mathrm{HCl}$
}

\author{
A.S. Fouda ${ }^{1, *}$, M. A. Diab ${ }^{2}$, and S. Fathy ${ }^{1}$ \\ ${ }^{1}$ Department of Chemistry, Faculty of Science, El-Mansoura University, El-Mansoura-35516, Egypt \\ ${ }^{2}$ Chemistry Department, Faculty of Science, Damietta University, New Damietta, Egypt \\ E-mail: asfouda@mans.edu.eg*
}

doi: $10.20964 / 2017.01 .60$

Received: 9 October 2016 / Accepted: 23 November 2016 / Published: 12 December 2016

The corrosion inhibitors, namely, (E)-3-oxo-2-(m-toyldiazenyl) pentanenitrile compound (A), (E)-3oxo-2-(phenyldiazenyl) pentanenitrile compound (B) and(E)-3-(phenyldiazenyl) pentane -2,4-dione compound (C) were influence on the corrosion of SS 316L in 1 Molar hydrochloric acid has been detected by utilized mas reduction, (EFM)electrical frequency modulation, tafel polarization, (EIS) method. Polarization value lead to this organic compound plays as mixed inhibitors kind. The temperature effect on corrosion protection had research on the adsorption parameters and activation thermodynamic measured. EIS was utilized to detect the technique of corrosion protection. EFM can be utilized a fast and non destructive test for record rate of corrosion. The adsorption follow Temkin's isotherm.

Keywords: SS 316L; HCl; organic derivatives, EFM; EIS

\section{$\underline{\text { FULL TEXT }}$}

(C) 2017 The Authors. Published by ESG (www.electrochemsci.org). This article is an open access article distributed under the terms and conditions of the Creative Commons Attribution license (http://creativecommons.org/licenses/by/4.0/). 